\title{
Nocturnal and respiratory disturbances in Steele-Richardson-Olszewski syndrome (progressive supranuclear palsy)
}

\author{
VS De Bruin, C Machado, RS Howard, NP Hirsch, AJ Lees
}

\begin{abstract}
Summary
Respiratory and sleep disturbances may be important causes of morbidity in Steele-Richardson-Olszewski syndrome but the frequency and character of nocturnal abnormalities remains uncertain. A prospective study of 11 patients with Steele-Richardson-Olszewski syndrome and age-matched control subjects was undertaken using clinical assessments, a structured sleep questionnaire, spirometry, static maximum inspiratory and expiratory pressures and nocturnal oximetry. The mean age of the SteeleRichardson-Olszewski syndrome patients was $63.2(52-70)$ years and mean disease duration was $4.0(2-6)$ years. There was moderate to severe motor disability in nine and mild to moderate dementia in eight. In the patients with SteeleRichardson-Olszewski syndrome the following abnormalities contributed to sleep disturbances significantly more frequently than in normal controls: depression, dysphagia, frequent nocturnal awakenings (usually associated with urinary frequency), immobility in bed, difficulty with transfers, impaired dressing and feeding. There was profound impairment of voluntary respiratory control whilst automatic and limbic control were well maintained. Nocturnal respiratory abnormalities were not present even in the most severely disabled. In Steele-Richardson-Olszewski syndrome sleep abnormalities are common; they relate to the cognitive, pseudobulbar and extrapyramidal disturbances and may therefore be amenable to symptomatic control.
\end{abstract}

The Harris/Batten

Unit, The National

Hospital for Neurology

and Neurosurgery,

Queen Square, London

WC1N 3BG, UK

VS De Bruin

C Machado

RS Howard

NP Hirsch

AJ Lees

Correspondence to

Dr RS Howard

Accepted 16 October 1995
Keywords: respiration, sleep, Steele-RichardsonOlszewski syndrome

Steele-Richardson-Olszewski syndrome (SROS) is a progressive, non-familial disorder beginning in middle or old age and characterised by a supranuclear ophthalmoplegia and at least two accompanying diagnostic features (box 1). ${ }^{1,2}$ Sleep disturbance is recognised as an important manifestation of SROS although, unlike idiopathic Parkinson's disease, ${ }^{3,4}$ the frequency, character and pattern of symptoms

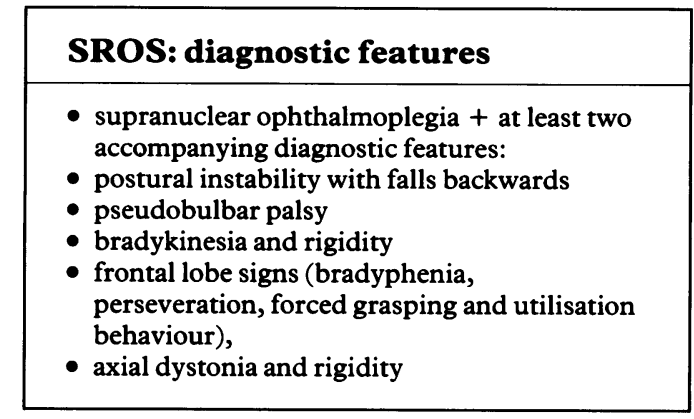

Box 1

due to such abnormalities remains unclear. Whilst there is a correlation between polysomnographic abnormalities and disease severity, the frequency and symptomatic significance of these disturbances of sleep pattern is uncertain. In idiopathic Parkinson's disease respiratory impairment is associated with upper airflow obstruction, ${ }^{5,6}$ reduced tidal volume, ${ }^{7}$ respiratory muscle weakness, ${ }^{6,8}$ restrictive defect due to respiratory muscle rigidity, ${ }^{9}$ abnormalities of central $\mathrm{CO}_{2}$ sensitivity ${ }^{10,11}$ and impairment of voluntary control. ${ }^{12}$ However, the pattern and severity of respiratory abnormalities in SROS are poorly described.

We undertook a study of consecutive patients with SROS and age-matched controls to estimate the frequency and character of sleep abnormalities and the incidence of nocturnal respiratory abnormalities.

\section{Methods}

We studied 11 patients with SROS fulfilling currently accepted clinical criteria ${ }^{1}$ and eight age- and sex-matched control subjects. There was no history of lung disease that might have led to structural or functional pulmonary dysfunction.

The clinical details included duration, severity and clinical features of the SROS. The patients underwent cognitive assessment including the Beck questionnaire, ${ }^{13}$ MiniMental state examination ${ }^{14}$ and detailed psychometric assessment including the Wechsler Adult Intelligence Scales. ${ }^{15}$ A structured sleep questionnaire was used for interviewing the patient and their carer about sleep history and habit. ${ }^{16}$ Spirometry and static maximum inspiratory and expiratory pressures were routinely 
assessed in all patients. ${ }^{17}$ All patients were carefully instructed in the techniques and took several practice attempts at each maneouver. The patients were studied for one night in an isolated darkened room. Oxygenation was measured continuously using an Ohmeda 3700 e pulse oximeter and transferred for subsequent computer analysis. ${ }^{18}$ The overnight basline oxygen saturation $\left(\mathrm{SpO}_{2}\right)$ and the number of dips in $\mathrm{SpO}_{2}>4 \%$ lasting longer than 10 seconds were calculated and expressed per hour of recording. ${ }^{19,20}$ The presence of sleep was documented by the nurse observing the patient but polysomnography was not performed because of the severity of the underlying disability. Comparison between the patients and control group was made using $\chi^{2}$ analysis. Values less than or equal to $<0.05$ were considered significant.

\section{Results}

Eleven patients with SROS (six male, five female) were studied with a mean age of $63.2 \pm 6.6(52-70)$ years and mean disease duration of $4.0 \pm 1.2(2-6)$ years. Eight healthy controls (five male, three female) with a mean age of $65.5 \pm 6.8$ (55-75) years. The clinical features at presentation are summarised in box 2. All the patients with SROS were aware of frequent falls associated with postural instability and a bradykinetic gait. Primitive reflexes included grasp, pout, palmo-mental and also imitation and utilisation behaviour. Two patients were independently mobile, three were mobile with aids, five required wheelchairs and one was bed-bound. The mean Mini Mental score $(n=8)$ was $21.6 \pm 7.5(13-28)$ years but even those patients with higher values were noted to perform the tests slowly. Mean performance IQ was 88.4 $\pm 11.1(77-101)$ and mean verbal IQ was $86.6 \pm 10.6(66-112)$. In the 10 patients in whom neuropsychological assessment was possible, nine showed generalised impairment of verbal and non-verbal memory, one impairment of non-verbal memory alone, five impairment of frontal lobe function, five difficulty in initiating tasks, slowness of execution, echolalia and perseveration, and two impairment of perception. There was evidence of moderate dementia in five patients, mild dementia in three and no dementia in three. There was clinical evidence of depression in

\begin{tabular}{|ll|}
\hline $\begin{array}{l}\text { SROS: clinical features at } \\
\text { presentation }\end{array}$ & \\
\hline - falls & 11 \\
- bradykinetic rigid syndrome & 11 \\
- dysarthria & 11 \\
- supranuclear downgaze palsy & 11 \\
- dysphagia & 9 \\
- pyramidal signs & 7 \\
- primitive reflexes & 7 \\
- emotionarospasm/apraxia of eyelid opening & 6 \\
- tremor & 3 \\
$n$ & 1 \\
\hline
\end{tabular}

Box 2 eight patients with a mean Beck score of $12.4 \pm 6.2$ with five scoring 16 or higher and three scoring six or below. Nine patients were receiving medication, these were sinemet (4), madopar (3), selegiline (2), amantidine (2), fluoxetine (1) and prothiadin (1).

Responses to the sleep questionnaire were compared with a series of aged-matched controls. In the patients with SROS the following abnormalities were reported by nine or more patients and were significantly more frequent than in normal controls: depression, fatigue, dysphagia, frequent nocturnal awakenings (usually associated with urinary frequency), immobility in bed, difficulty with transfers, impaired dressing and feeding (box 3). The following abnormalities were more frequent in patients with SROS but did not reach statistical significance: hypersomnolence, reduced daytime alertness, daytime naps and a tendency to wake because of choking.

Spirometry and maximum inspiratory and expiratory pressure measurements were attempted in both patients and controls. The patients with SROS experienced extreme difficulties in performing the motor tasks of voluntary full inspiration and expiration and also forced inspiratory and expiratory manoeuvres. This seemed to be firstly because of a combination of cognitive impairment leading to difficulty understanding the commands and a particular problem being experienced in placing the mouthpiece between the lips (in the absence of any facial weakness) and in performing forced expiration to command. Secondly there was a profound slowness and perseveration in response to command and an inability to execute the complex motor manoeuvres despite adequate power, however, respiratory patterns did vary in response to emotional stimuli. It was therefore not possible to perform an adequate assessment of lung volumes or respiratory muscle strength.

All the patients had a regular breathing pattern whilst awake with a mean baseline $\mathrm{SaO}_{2}$ of $95 \%(94-97 \%)$. There were infrequent hypoxic dips of $4 \%$ below baseline in three patients but in none of these patients did the rate of hypoxic dips equal or exceed five/hour. The minimum saturations were $90 \%, 91 \%$ and $92 \%$. Therefore, in all cases nocturnal oximetry was within normal limits.

\section{Discussion}

Previous polysomnographic studies in patients with SROS have shown that, with increasing

\begin{tabular}{|l|}
\hline SROS: factors associated with \\
noctural disturbance \\
\hline - depression \\
- fatigue \\
- dysphagia \\
- urinary frequency \\
- immobility \\
\hline
\end{tabular}


disease severity, there is a reduction in total sleep time with large amounts of wakefulness interspersed throughout sleep, frequent early morning awakenings, prolonged latency of sleep onset and a progressive loss of the number and duration of episodes of REM sleep. ${ }^{21-25}$ Despite extensive and detailed polysomnographic studies there is no previous analysis of the frequency with which symptoms of nocturnal disturbance occur in SROS. Although insomnia is well described in SROS only four patients in the present series were aware of a difficulty in sleeping. However, patients were troubled by frequent nocturnal awakenings associated with urinary urgency and nocturia. Patients were also distressed by severe immobility due to rigidity, this led to difficulties in finding a comfortable position in which to sleep and difficulties with transfers out of bed. The rigidity also led to severe impairments of dressing and feeding which contribute to the overall morbidity of the condition.

Sleep-related behaviour disturbances are considered to be common during the latter stages of the disease. ${ }^{21}$ This was not a prominent feature in the present series in whom vivid dreams, nocturnal movements and disorientation were rare. This may be because the severe rigidity prevents dystonia or involuntary movements becoming manifest or because these abnormalities usually occur during REM sleep which is much reduced.

Previous reports of sleep-related respiratory abnormalities in SROS have suggested that obstructive, central or mixed apnoeas may occur but that these are mild and make only a minor contribution to sleep disturbance without contributing to respiratory insufficiency. ${ }^{25,26}$ In the present series nocturnal respiration was extremely well preserved with no significant sleep apnoea in any patient, regardless of the severity of disability. Although automatic respiration was apparently normal in this study there was a profound disturbance of voluntary (behavioural) control of respiration manifest as difficulty performing voluntary inspiration and expiration, breath holding and complex motor manoeuvres to command. ${ }^{27}$ Behavioural control of respiration is mediated by rapidly conducting oligosynaptic pathways from the contralateral motor cortex descending with corticospinal and corticobulbar fibres in the lateral

1 Lees AJ. The Steele-Richardson-Olszewski syndrome (progressive supranuclear palsy). Mov Disord 1987; 2: 272-87. 2 Maher ER, Lees AJ. The clinical features and natural history of the Steele-Richardson-Olszewski syndrome (progressive of the Steele-Richardson-Olszewski syndrome (pro
supranuclear palsy). Neurology 1986; 36: 1005-8.

3 Lees AJ, Blackburn NA, Campbell VL. The nighttime

Lees AJ, Blackburn NA, Campbell VL. The nighttime
problems of Parkinson's disease. Clin Pharmacol 1988; 6: problems

4 Factor SA, McAlarny T, Sanchez-Ramos JR, Weiner WJ. Sleep disorders and sleep effects in Parkinson's disease. Mov Disord 1990; 5: 280-5.

5 Vincken WG, Gauthier SG, Dollfuss RE, Hanson RE, Darauay CM, Cosio MG. Involvement of the upper airway muscles in extrapyramidal disorders. $N$ Engl $\tilde{f}$ Med 1984; 311: 438-42.

6 Hovestadt A, Bogaard JM, Meernaldt JD, van der Merche FGA, Stigt J. Pulmonary function in Parkinson's disease. $\mathcal{F}$ Neurol Neurosurg Psychiatry 1989; 52: 329-33.

7 Apps MCP, Sheaf PC, Ingram DA, Kennard C, Empey

DW. Respiration and sleep in Parkinson's disease. $\mathcal{F}$ Neurol Neurosurg Psychiatry 1985; 48: 12-45.

\section{Key points}

- nocturnal disturbance is common and may be amenable to symptomatic treatment

- nocturnal respiratory insufficiency is rare

- there is a supranuclear impairment of ventilatory control (ie, disrupted voluntary control but well maintained automatic and limbic control)

\section{Box 4}

columns. ${ }^{28}$ Selective interruption of voluntary pathways leads to a strikingly regular and unvarying respiratory pattern during which the patient is unable to take a deep breath, hold the breath, cough voluntarily or initiate any kind of volitional. respiratory movements. ${ }^{29} \mathrm{~A}$ related phenomenon of respiratory apraxia has been described in patients with Cheyne-Stokes respiration, ${ }^{30}$ however, the respiratory pattern in this condition is not a true apraxia as the fixed pattern is obligate on abnormalities of central respiratory control and slowed circulation. The present series suggests that in SROS lesions of the corticobulbar pathways causing pseudobulbar palsy lead to a partial functional interruption of the behavioural pathways. The resultant supranuclear disturbances of respiration may cause severe motor retardation and impairment of the capacity to perform respiratory tasks to command. However, the apparent preservation of limbic ventilatory reponses suggests that separate descending systems mediating emotional control were intact. $^{31}$

The present study of 11 consecutive patients with SROS suggests that nocturnal abnormalities are common and relate to the severity of neurological disability and cognitive function (box 2). Nocturnal disturbance is usually associated with depression, fatigue, dysphagia, urinary frequency, immobility and impaired dressing and feeding. Nocturnal respiratory abnormalities are rarely symptomatic but the patients did show a supranuclear impairment of respiratory control manifest as a profound impairment of voluntary respiratory control whilst maintaining automatic and limbic emotional control of breathing.

8 Estenne $M$, Hubert $M$, de Troyer A. Respiratory muscle involvement in Parkinson's disease. N Engl f Med 1984; 311: involvem.

9 Ilson J, Braun N, Fahn S. Respiratory fluctuations in Ilson J, Braun N, Fahn S. Respiratory fluctuations
Parkinson's disease. Neurology 1983; 33 (suppl 2): 113.

$10 \mathrm{Da}$ Costa JL. Chronic hypoventilation due to diminished sensitivity of the respiratory centre associated with parkinsonism. Med F Aust 1972; 1: 373-6.

11 Feinsilver SH, Friedman JH, Rosen JM. Respiration and sleep in Parkinson's disease. $\mathfrak{f}$ Neurol Neurosurg Psychiatry 1985; 48: 964.

12 Apps MCP, Hughes DTD, Empey DW. Breath holding in normal subjects and in patients with Parkinson's disease. $\mathcal{F}$ Physiol 1984; 83P: C65.

13 Steer RA, Beck AT, Garrison B. Application of the Beck depression inventory. In: Sartorius N, Ban T, eds. Assessment of depression. Heidelberg: Springer Verlag, 1986.

14 Dick JPR,. Guiloff RJ, Stewart A, et al. Mini-mental state examination in neurological patients. $\mathcal{F}$ Neurol Neurosurg
Psychiatry 1984; 47: 496-9. 
15 Wechsler D. WAIS-R manual. New York: Psychological Corporation, 1981.

16 Tachibana N, Howard RS, Hirsch NP, Miller DH, Moseley IF, Fish D. Sleep problems in multiple sclerosis. Eur Neurol 1994; 34: 320-3.

17 Black LE, Hyatt RE. Maximal static respiratory pressures in generalised neuromuscular disease. Am Rev Respir Dis 1971; 103: $641-50$

18 Warley ARH, Stradling JR, Michell J. Evaluation of the Ohmeda 3700 pulse oximeter. Thorax 1987; 42: 892-6.

19 Cooper BG, Veale D, Griffiths CJ, Gibson GJ. Value of nocturnal oxygen saturation as a screening test for sleep apnoea. Thorax 1991; 46: 586-8.

20 George CF, Millar TW, Kryger MH. Identification and quantification of apneas by computer-based analysis of quantification of apneas by computer-based analysis of

21 Gross RA, Spehlmann R, Daniels JC. Sleep disturbances in progressive supranuclear palsy. Electroencephalogr Clin Neurophysiol 1978; 45: 16-25.

22 Laffont F, Autret A, Minz M, et al. Etude polygraphique du sommeil dans 9 cas de maladie de Steele-Richardson. Rev Neurol 1979; 135: 127-42.

23 Leygonie F, Thomas J, Degos JD, Bouchareine A, Barbizet Steele-Richardson. Rev Neurol 1976; 132: 125-36.
24 Perret JL, Jouvet M. Etude du sommeil dans la paralysie supra-nucleaire progressive. Electroencephalogr Clin Neurophysiol 1980:

25 Aldrich MS, Foster NL, White RF, Blemlein L, Prokopowicz $\mathrm{G}$. Sleep abnormalities in progressive supranuclear palsy. Am Neurol 1989; 25: 577-81.

26 Aldrich MS. Sleep disturbance. In: Litvan I, Agid Y, eds. Progressive supranuclear palsy. Oxford: Oxford University Press, 1992; pp 169-83.

27 Plum F. Neurological integration of behavioural and metabolic control of breathing. In: Parker R, ed. Breathing : Hering-Breuer Centenary Symposium. London: Churchill, 1970; pp 159-83.

28 Howard RS, Newsom Davis J. Neural control of respiration. In: Crockard A, Hayward R, Hoff JT, eds. Neurosurgery the scientific basis of clinical practice, 2nd edn. Oxford: the scientific basis of clinical

29 Meyers JC, Herndon RM. Bilateral infarction of the Meyers JC, Herndon RM. Bilateral infarction of

pyramidal tracts in man. Neurology 1962; 12: 637-42.
30 Herbertson WM, Talbert OR, Cohen ME. Respiratory apraxia and anosognosia. Trans Am Neurol Assoc 1959; 176-9.

31 Munschauer FE, Mador MJ, Ahuja A, Jacobs L. Selective paralysis of voluntary but not limbically influenced automatic respiration. Arch Neurol 1991; 48: 1190-2. 